\title{
REGULAÇÃO JURÍDICA DO TRABALHO DOMÉSTICO NO BRASIL: DISCRIMINAÇÃO INTERSECCIONAL E RESISTÊNCIA À PROTEÇÃO TRABALHISTA
}

\author{
Dissertação de Mestrado
}

Orientador: Professor Associado Dr. Antonio Rodrigues de Freitas Júnior

UNIVERSIDADE DE SÃO PAULO

FACULDADE DE DIREITO

São Paulo - SP 



\section{REGULAÇÃO JURÍDICA DO TRABALHO DOMÉSTICO NO BRASIL: DISCRIMINAÇÃO INTERSECCIONAL E RESISTÊNCIA À PROTEÇÃO}

TRABALHISTA

Dissertação apresentada à Banca Examinadora do Programa de Pós-Graduação em Direito, da Faculdade de Direito da Universidade de São Paulo, como exigência parcial para obtenção do título de Mestre em Direito, na área de concentração de Direito do Trabalho e da Seguridade Social.

Orientador: Professor Associado Dr. Antonio Rodrigues de Freitas Júnior.

UNIVERSIDADE DE SÃO PAULO

FACULDADE DE DIREITO

São Paulo - SP 
Autorizo a reprodução e divulgação total ou parcial deste trabalho, por qualquer meio convencional ou eletrônico, para fins de estudo e pesquisa, desde que citada a fonte.

Catalogação da Publicação

Serviço de Processos Técnicos da Biblioteca da Faculdade de Direito da Universidade de São Paulo

\section{Stratton, Ana Beatriz Koury}

Regulação jurídica do trabalho doméstico no Brasil: discriminação interseccional e resistência à proteção trabalhista /Ana Beatriz Koury Stratton; orientador Antonio Rodrigues de Freitas Júnior -- São Paulo, 2017.

$154 \mathrm{f}$.

Dissertação (Mestrado - Programa de Pós-Graduação em Direito do Trabalho e da Seguridade Social) - Faculdade de Direito, Universidade de São Paulo, 2017.

1. Empregadas domésticas. 2. Discriminação interseccional. 3. Legislação trabalhista - Brasil. 4. Organização das empregadas domésticas.

I. Freitas Júnior, Antonio Rodrigues de, orient. II. Título. 
STRATTON, Ana Beatriz Koury. Regulação jurídica do trabalho doméstico no Brasil: discriminação interseccional e resistência à proteção trabalhista. Dissertação apresentada à Banca Examinadora do Programa de Pós-Graduação em Direito, da Faculdade de Direito da Universidade de São Paulo, como exigência parcial para obtenção do título de Mestre em Direito, na área de concentração de Direito do Trabalho e da Seguridade Social, sob a orientação do Professor Associado Dr. Antonio Rodrigues de Freitas Júnior.

Data de aprovação:

\section{BANCA EXAMINADORA}

Prof. Dr. Instituição:

Julgamento: Assinatura:

Prof. Dr. Instituição:

Julgamento: Assinatura:

Prof. Dr. Instituição:

Julgamento: Assinatura: 

As mulheres que trabalham ou trabalhavam como empregadas domésticas, que, de uma forma ou de outra, passaram pela minha vida, influenciaram minha percepção sobre a profissão e me inspiraram na elaboração deste trabalho. 



\section{AGRADECIMENTOS}

Agradeço ao Darryl, meu melhor amigo e companheiro de todas as horas, pelo amor, carinho, cuidado, por sempre acreditar em mim e nos meus sonhos.

À minha querida mãe, por me inspirar confiança e pelas conversas diárias, tão importantes nos anos de estudo para o Mestrado. Ao meu amado pai, com que tenho a honra de compartilhar o amor pelo Direito do Trabalho e pelo mundo acadêmico. Ao meu brilhante irmão, por me puxar sempre para o alto. À minha sobrinha, Lulu, por trazer alegria às nossas vidas. À Vó Ana e à Vó Gênia, dois anjos que, tenho certeza, não deixam de torcer por mim. Ao Ed e à Judy, que sempre demonstram interesse nos meus projetos e estão presentes, mesmo que fisicamente distantes. À Fabi e à Ritinha, amigas queridas, que, a cada encontro e risadas, me fizeram sentir em casa em São Paulo.

Ao Professor Freitas, por me abrir as portas da USP, pelo constante estímulo à pesquisa, pelo compartilhamento de conhecimento e, principalmente, pela sensibilidade em compreender as várias fases por que passamos até a conclusão da dissertação.

Aos amigos Fernando Bosi e Denise Valente, pela ajuda imensurável no processo de seleção do Mestrado. Ao Gustavo Seferian, por permitir meu primeiro contato com a "SanFran", por meio do Grupo de Pesquisa Trabalho e Capital, que me introduziu no lado mais apaixonante do Direito do Trabalho. Às queridas Jana, Marilu e Katbe, presenças constantes nas disciplinas da pós-graduação, que contribuíram para que cada aula fosse ainda mais especial e divertida. À Marlene Seiffarth, que tive o prazer de conhecer em Genebra, por reforçar minha crença na importância da investigação do emprego doméstico no Brasil.

À Professora Helena Hirata e todas as colegas da disciplina Sociologia do Trabalho, do Gênero e do "Care", cursada no segundo semestre de 2014, por incríveis momentos e conhecimentos compartilhados nas tardes de quarta-feira, que ajudaram a abrir minha visão sobre o trabalho doméstico.

Por fim, e mais importante, a Deus, por colocar todas essas pessoas maravilhosas na minha vida e pela força que não me deixou desistir. 

A carne mais barata do mercado é a carne negra

Que vai de graça pro presídio

E para debaixo do plástico

Que vai de graça pro subemprego

E pros hospitais psiquiátricos

Que fez e faz história

Segurando esse país no braço

O cabra aqui não se sente revoltado

Porque o revólver já está engatilhado

E o vingador é lento

Mas muito bem intencionado

E esse país

Vai deixando todo mundo preto

E o cabelo esticado

Mas mesmo assim

Ainda guardo o direito

De algum antepassado da cor

Brigar sutilmente por respeito

Brigar bravamente por respeito

Brigar por justiça e por respeito

De algum antepassado da cor

Brigar, brigar, brigar

Elza Soares, A Carne (2002) 



\section{RESUMO}

STRATTON, Ana Beatriz Koury. Regulação jurídica do trabalho doméstico no Brasil: discriminação interseccional e resistência à proteção trabalhista. 2017. 154f. Dissertação (Mestrado) - Faculdade de Direito, Universidade de São Paulo, São Paulo, 2017.

A pesquisa tem como objetivo analisar e tentar compreender a privação dos direitos trabalhistas das empregadas domésticas no Brasil, que foi perpetrada ao longo dos anos e que é visível em diversos diplomas legais. Exemplo disso é a redação do artigo $7^{\circ}$ da Constituição Federal de 1988, que no caput assegura direitos trabalhistas aos trabalhadores "urbanos e rurais" e no parágrafo único enumera, separadamente, alguns direitos aos quais fazem jus as trabalhadoras domésticas, que não contam com a mesma proteção social dos demais trabalhadores. A não concessão plena dos direitos trabalhistas foi consagrada pela regulamentação da Emenda Constitucional 72/2013, por meio da Lei Complementar 150/2015, que excluiu da proteção social todas aquelas que trabalham no ambiente doméstico por até dois dias por semana. É central para a presente investigação a busca do que verdadeiramente está por trás dessa privação de direitos, até mesmo na tentativa de refutar eventuais justificativas falaciosas para a discriminação da categoria. Para isso, é fundamental traçar o perfil de gênero, classe e raça das empregadas domésticas no Brasil composta por uma maioria de mulheres, negras e pobres -, analisado a partir das ideias da divisão sexual do trabalho, da bipolarização do trabalho feminino e da herança escravista do emprego doméstico. Todas essas ideias devem ser tratadas de forma conjunta, interligadas, mas não hierarquizadas, conforme indicado pela teoria da interseccionalidade, a fim de que se possa avaliar a real dimensão da marginalização. Por fim, pretende-se destacar que, para atingir o atual estágio de regulamentação jurídica do emprego doméstico, foram essenciais a organização das empregadas domésticas e a luta das representantes da categoria, cujas vozes não podem mais ser abafadas.

Palavras-chave: Empregadas domésticas. Discriminação interseccional. Legislação trabalhista - Brasil. Organização das empregadas domésticas. 



\begin{abstract}
STRATTON, Ana Beatriz Koury. Legal regulation of domestic work in Brazil: intersectional discrimination and resistance to labor protection. 2017. 154p. Dissertation (Master's Degree) - Law School, Universidade de São Paulo, São Paulo, 2017.

The research aims at analyzing and understanding the deprivation of labor rights of female domestic workers in Brazil that has been perpetrated over the years and is evident in several legal statutes. An example of this is the wording of Section 7 of the Brazilian Constitution of 1988, which ensures the labor rights to "urban and rural" workers in its head provision, but, in the single paragraph, separately lists some rights of female domestic workers, who do not have the same social protection as other workers. The failure to fully grant labor rights has been enshrined in the provisions of the Constitutional Amendment No. 72/2013, through Complementary Law No. 150/2015, which excluded all those persons working in the domestic environment for up to two days a week from social protection. The pursuit of what is truly behind this deprivation of rights is critical for this research, even in an attempt to refute any fallacious justifications for the discrimination of the professional category. Therefore, it is fundamental to establish the profile of female domestic workers in Brazil - which is predominantly composed of black and poor women - regarding gender, social standing, and race, and analyze it based on the concepts of sexual division of labor, bipolarization of women's work and slaveholding heritage of the domestic work. All these ideas should be handled together, in a connected but not in a ranked manner, as indicated by the theory of intersectionality, in order to assess the true scale of marginalization. Finally, the research also intends to highlight that the organization of female domestic workers and the struggle of representatives of the professional category, whose voices can no longer be suppressed, were critical for reaching the current stage of legal regulation of domestic work.
\end{abstract}

Keywords: Female domestic workers. Intersectional discrimination. Labor law - Brazil. Organization of female domestic workers. 



\section{LISTA DE GRÁFICOS}

Gráfico 1 - Proporção de trabalhadores precarizados na população ocupada de 16 anos de idade ou mais, segundo cor/raça e sexo. Brasil, 2004 a 2014.

Gráfico 2 - Proporção de trabalhadoras domésticas entre as mulheres ocupadas de 10 anos ou mais de idade, segundo cor/raça. Brasil, 2004 a 2014.

Gráfico 3 - Proporção de trabalhadoras domésticas por grupos de idade. Brasil, 2004 a 2014. 38

Gráfico 4 - Proporção de trabalhadoras domésticas por grupos de idade e cor/raça. Brasil, 2004 a 2014

Gráfico 5 - Proporção de trabalhadoras domésticas com carteira de trabalho assinada por cor/raça. Brasil, 2004 a 2014.

Gráfico 6 - Proporção de trabalhadoras domésticas que prestam serviço em mais de um domicílio. Brasil, 2004 a 2014.

Gráfico 7 - Distribuição percentual de trabalhadoras domésticas por tipo de trabalho (em um ou mais de um domicílio) e acesso a carteira de trabalho, segundo cor/raça. Brasil, 2004 e 2014.

Gráfico 8 - Renda média das trabalhadoras domésticas, segundo acesso à carteira de trabalho. Brasil 2004 a 2014.

Gráfico 9 - Rendimento médio mensal das trabalhadoras domésticas por cor/raça. Brasil 2004 a 2014.

Gráfico 10 - Renda média das trabalhadoras domésticas, segundo tipo de trabalho (em um ou mais de um domicílio). Brasil, 2004 a 2014. 



\section{LISTA DE QUADROS}

Quadro 1- Fases de concessão dos direitos trabalhistas constitucionais às empregadas domésticas.

Quadro 2 - Linha do tempo da organização das empregadas domésticas no Brasil....... 132 



\section{LISTA DE ABREVIATURAS E SIGLAS}

AFS

AIRR

CAS

$\mathrm{CBO}$

CCGR

CELADE

CLT

COLACTRAHO

CR

CTPS

CUT

DISOC

EC

EUA

FENATRAD

FGTS

GM

IBGE

ILO

IN

INPC

IPEA

LC

LGBT

MNE

MTE

NINSOC

OEA

OIT

ONG

ONU

PEA
Associação Francesa de Sociologia

Agravo de Instrumento em Recurso de Revista

Comissão de Assuntos Sociais

Classificação Brasileira de Ocupações

Comitê Gestor de Gênero e Raça

Centro Latino-Americano e Caribenho de Democracia

Consolidação das Leis Trabalhistas

Confederación Latinoamericana y del Caribe de Trabajadoras del Hogar

Constituição da República Federativa do Brasil

Carteira de Trabalho e Previdência Social

Central Única de Trabalhadores

Diretoria de Estudos Políticas Sociais

Emenda Constitucional

Estados Unidos

Federação Nacional das Trabalhadoras Domésticas

Fundo de Garantia do Tempo de Serviço

General Motors

Instituto Brasileiro de Geografia e Estatística

International Labour Organization

Instrução Normativa

Índice Nacional de Preços ao Consumidor

Instituto de Pesquisa Econômica Aplicada

Lei Complementar

Lésbicas, Gays, Bissexuais, Travestis, Transexuais e Transgêneros.

Movimento Negro Unificado

Ministério do Trabalho e Emprego

Núcleo de Gestão de Informações Sociais

Organização dos Estados Americanos

Organização Internacional do Trabalho

Organização Não Governamental

Organização das Nações Unidas

Pessoas Economicamente Ativas 
Proposta de Emenda Constitucional

PIS

Programa de Integração Social

PNAD

Pesquisa Nacional por Amostra de Domicílios

PPIOPT

Programa de Promoção da Igualdade de Oportunidade para Todos

RO

Recurso Ordinário

$\mathrm{RR}$

Recurso de Revista

SCD

Substitutivo da Câmara dos Deputados

SINE

Site Nacional de Empregos

STJ

Superior Tribunal de Justiça

TRT

Tribunal Regional do Trabalho

TST

Tribunal Superior do Trabalho

UNICEF

Fundo das Nações Unidas para a Infância 


\section{SUMÁRIO}

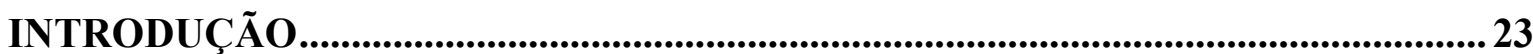

1 O PERFIL DAS EMPREGADAS DOMÉSTICAS NO BRASIL...............................33

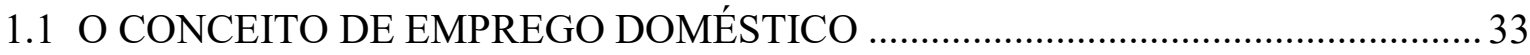

1.2 DADOS ESTATÍSTICOS SOBRE O EMPREGO DOMÉSTICO NO BRASIL.........34

1.3 TRABALHO EXECUTADO MAJORITARIAMENTE POR MULHERES ...............46

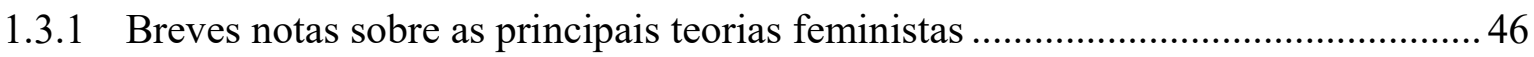

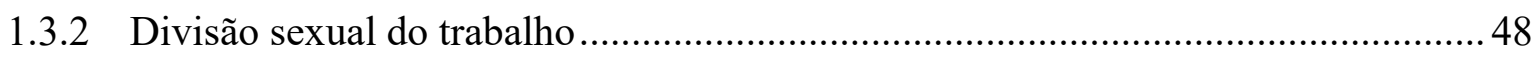

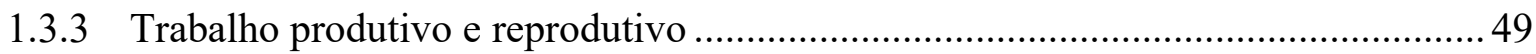

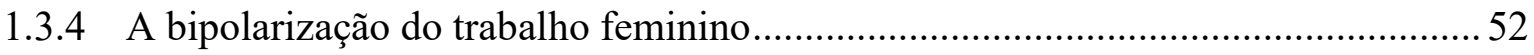

1.4 A IMPORTÂNCIA DE UMA ANÁLISE INTERSECCIONAL DO EMPREGO

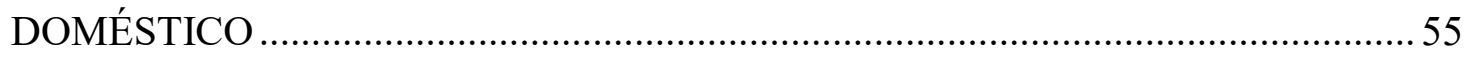

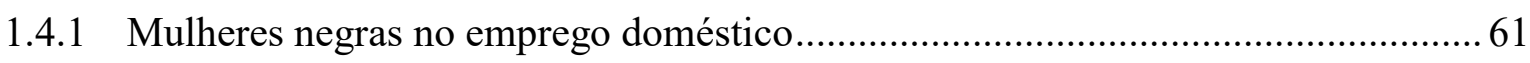

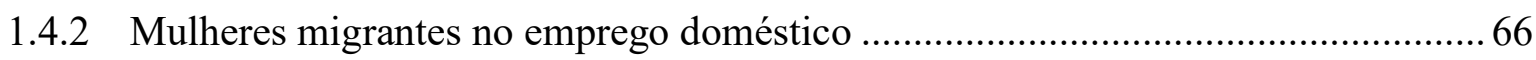

2 DISCRIMINAÇÃO DAS EMPREGADAS DOMÉSTICAS NA

LEGISLAÇÃO TRABALHISTA BRASILEIRA ….................................................. 73

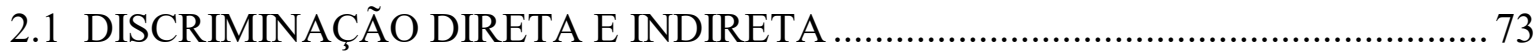

2.2 (DES)REGULAMENTAÇÃO DO EMPREGO DOMÉSTICO NO BRASIL ........... 74

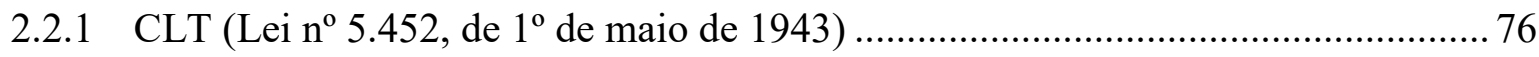

2.2.2 Lei $\mathrm{n}^{\mathrm{0}}$ 5.859, de 11 de dezembro de 1972 ........................................................... 78

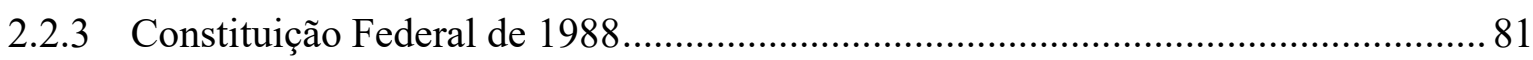

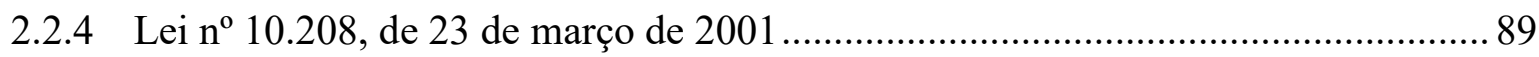

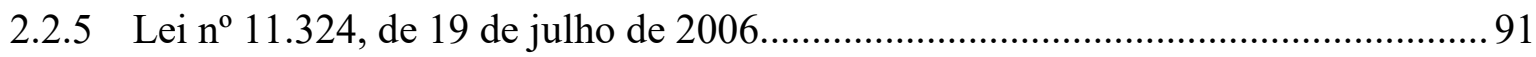

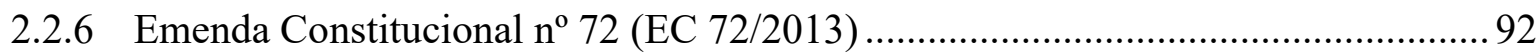

2.3 A LEI COMPLEMENTAR 150/2015 E O FUTURO DO EMPREGO

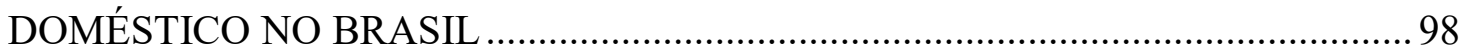

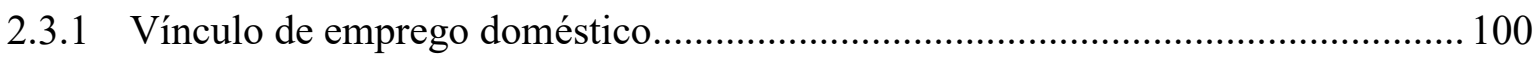

2.3.2 Jornada de trabalho das empregadas domésticas ............................................ 107

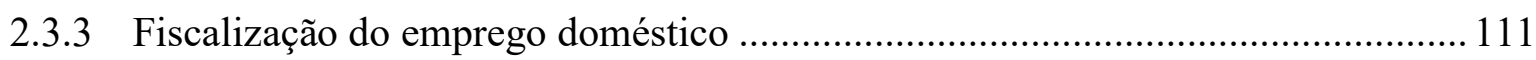

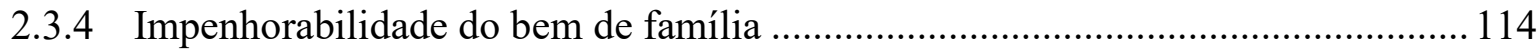

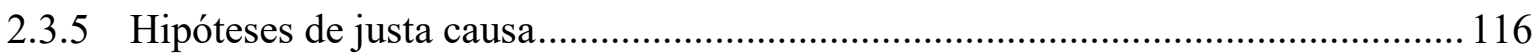




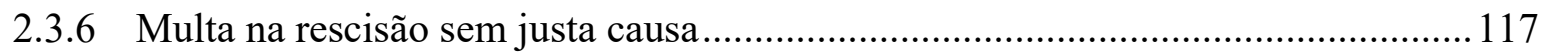

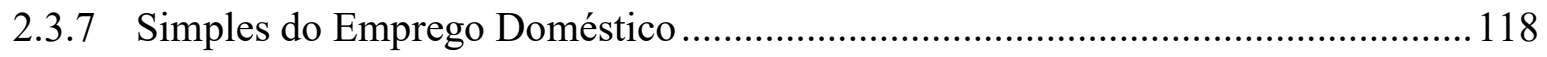

3 ORGANIZAÇÃO DAS EMPREGADAS DOMÉSTICAS NO BRASIL .................121

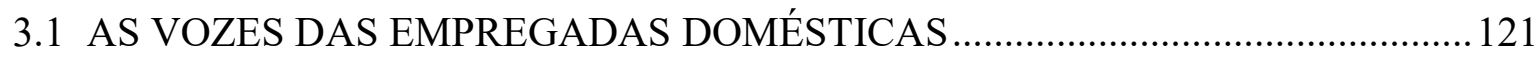

3.2 OBSTÁCULOS À ORGANIZAÇÃO DAS EMPREGADAS DOMÉSTICAS ......... 124

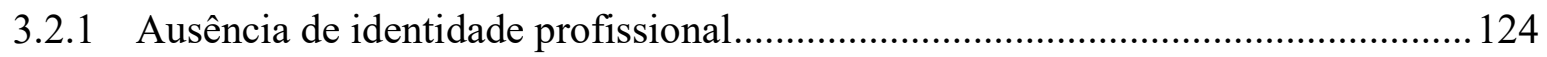

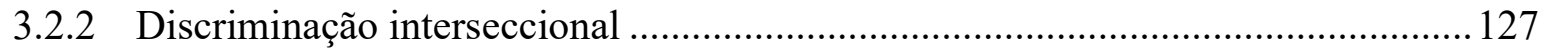

3.3 OBSTÁCULOS JURÍDICOS À ORGANIZAÇÃO DAS EMPREGADAS

DOMÉSTICAS E A EMENDA CONSTITUCIONAL 72/2013 _................................ 129

3.4 HISTÓRIA DA ORGANIZAÇÃO DAS EMPREGADAS DOMÉSTICAS NO

BRASIL E A CONVENÇÃO N 189 DA OIT …....................................................... 131

3.4.1 Associação das Empregadas Domésticas em Santos .......................................... 132

3.4.2 Sindicato das Trabalhadoras Domésticas de Campinas ........................................ 134

3.4.3 Sindicato das Trabalhadoras Domésticas do Estado da Bahia ............................. 135

3.4.4 Federação Nacional das Trabalhadoras Domésticas ............................................ 137

3.4.5 A luta pela aprovação da Convenção no 189 da OIT ............................................ 138

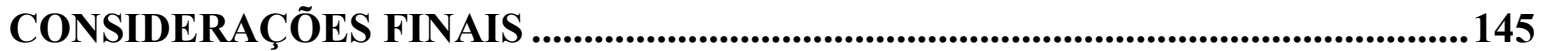

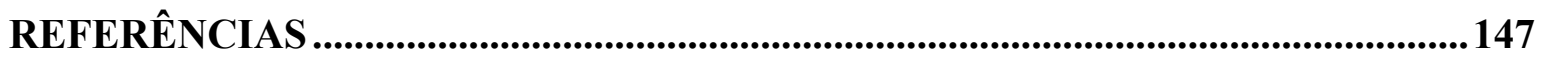




\section{INTRODUÇÃO}

Nunca tive dúvidas quanto à escolha do objeto de pesquisa da presente dissertação: o emprego doméstico no Brasil. Isso porque é preciso tentar compreender a exclusão perpetrada, entre outros diplomas legais, pela redação do artigo $7^{\circ}$ da Constituição Federal de 1988 (CR/88), que no caput assegura direitos trabalhistas aos trabalhadores "urbanos e rurais" e no parágrafo único enumera, separadamente, alguns direitos aos quais fazem jus as trabalhadoras domésticas ${ }^{1}$, que não contam com a mesma proteção social dos demais trabalhadores.

Nos anos que antecederam a aprovação da Emenda Constitucional 72 (EC/72) em 2012, antes da superexposição na mídia da Proposta de Emenda Constitucional, a denominada "PEC das domésticas", que viria a estender às domésticas alguns direitos trabalhistas aos quais já faziam jus os demais trabalhadores, o estudo do emprego doméstico na seara do Direito do Trabalho parecia esgotado, talvez pela inexistência de novo marco regulatório. Tanto é verdade que, a título de exemplo, em pesquisa realizada por teses e dissertações defendidas na Faculdade de Direito da Universidade de São Paulo, por meio do banco de dados Dedalus ${ }^{2}$, utilizando o critério de busca pelos termos emprego doméstico, empregada doméstica, empregado doméstico, empregadas domésticas e empregados domésticos nos títulos das pesquisas, foram localizados apenas três trabalhos ${ }^{3}$ datados dos anos de 1980, 2013 e 2016.

Nesse mesmo sentido, para apurar a divulgação dos estudos sobre trabalho doméstico, Jurema Brites realizou em 2013 um levantamento em dois renomados sistemas repositórios de artigos com acesso livre por meio da internet, o SciELO e Redalyc.2, que divulgam, principalmente, a produção acadêmica do Brasil e da América Latina. O resultado foi setenta e um artigos, somando a produção encontrada em ambos os sistemas, distribuídos entre as seguintes áreas: "sociologia, com 26 indicações; psicologia, com 10; antropologia,

\footnotetext{
No presente trabalho, optou-se pelo uso do feminino em referência às empregadas domésticas.

SIBI. Sistema Integrado de Bibliotecas - Universidade de São Paulo. Dedalus. São Paulo, 2017. Disponível em: <http://dedalus.usp.br/F/P58185MINSU3J5UX2R2P9QPHQRYHCHMC27DM87KIDDF R6HHVK248872?RN=794954223\&pds_handle=GUEST $>$. Acesso em: 24 mar. 2017.

3 Cf. LUCA, Carlos Moreira de. Relação de emprego doméstico: o contrato de emprego doméstico no direito brasileiro do trabalho. 1980. Dissertação (Mestrado em Direito) - Universidade de São Paulo, São Paulo, 1980; BARROS, Veronica Altef. Qualificação profissional do trabalhador doméstico no Brasil: análise na perspectiva do trabalho decente. 2013. Tese (Doutorado em Direito) - Universidade de São Paulo, São Paulo, 2013; SILVA, Isadora Brandão Araujo da. Da invisibilização ao reconhecimento institucional: limites da proteção jurídica das empregadas domésticas. 2016. Dissertação (Mestrado em Direito) - Universidade de São Paulo, São Paulo, 2016.
} 
com 8; ciências sociais, com 5; saúde, com 5; história, com 3; e mais 7 áreas com apenas uma indicação cada"4 . O Direito não constava da lista.

Os estudos jurídicos sobre o emprego doméstico intensificaram-se a partir das fervorosas discussões sobre a denominada "PEC das domésticas". A grande maioria de textos sobre o tema buscava fazer um paralelo entre os direitos assegurados às domésticas pela Constituição de 1988 e aqueles estendidos pela Emenda Constitucional no 72 . Vale pontuar que, ainda sem grandes novidades legislativas sobre o tema, nunca se perdeu a necessidade de ser feita uma análise crítica sobre a privação de direitos às empregadas domésticas perpetrada ao longo dos anos.

Felizmente, as lacunas na pesquisa sobre o emprego doméstico no Direito do Trabalho não eram percebidas, na mesma proporção, em outras áreas do conhecimento. ${ }^{5}$ Ao contrário, os estudos que foram e vêm sendo desenvolvidos nas searas, principalmente, da sociologia, antropologia e história são indispensáveis para a compreensão do emprego doméstico no Brasil. Apenas a partir dessas valiosas pesquisas podemos começar a compreender a razão de ser da lenta proteção legal trabalhista concedida às empregadas domésticas. Serão citados aqui alguns estudos que mais influenciaram o presente trabalho, sem a pretensão de se tratar de uma lista exaustiva do que há de mais relevante sobre o tema.

Heleieth Saffioti é referência nacional e internacional no estudo sobre a condição feminina e, em 1967, defendeu sua tese de livre-docência, sob a orientação de Florestan Fernandes, denominada "A mulher na sociedade de classes: mito e realidade" ${ }^{\text {. O }}$ pioneirismo do seu trabalho se dá, inclusive, pela até então escassa circulação no Brasil dos textos de Marx, de estudiosos marxistas e de pesquisadoras feministas de outras nacionalidades, todos com grande influência nos seus estudos. ${ }^{7}$

Nesse seu primeiro livro, Safiotti investigou os laços que unem a opressão feminina e o modo de produção capitalista. Ela afirmava que a força de trabalho é diferenciada em termos de sexo e raça e que “[...] o modo de produção capitalista

4 BRITES, Jurema. Trabalho doméstico: questões, leituras e políticas. Cadernos de Pesquisa, v. 43, n. 149, 2013, p. 426.

5 Ainda assim, "pesquisadores e pesquisadoras sobre trabalho doméstico costumam dizer que há uma desproporção entre a expansão do fenômeno na realidade e a produção acadêmica sobre ele. Durante muito tempo, contávamos com poucos autores para apoiar nossos caminhos de investigação. Pouco a pouco, o tema do trabalho doméstico tem tornado à cena e o campo conta com uma produção significativa e de certo vulto, embora ainda pouco disseminada entre os leitores da área das ciências humanas" (cf. ibid., p. 425).

6 SAFFIOTI, Heleieth Iara Bongiovani. A mulher na sociedade de classes: mito e realidade. 3. ed. São Paulo: Expressão Popular, 2013.

7 GONÇALVES, Renata. Prefácio. In: ibid., p. 16. 
potencializa a marginalização de certos setores da população do sistema produtivo"8. Além disso, apresentou conclusão em sentido oposto aos que entendiam que "[...] o capitalismo abria portas para a emancipação feminina por meio da entrada das mulheres no mercado de trabalho" ". Segundo a autora, o "[...] modo de produção capitalista alija força de trabalho do mercado, especialmente a feminina. Os caracteres raciais e de sexo operam 'como marcas sociais que permitem hierarquizar, segundo uma escala de valores, os membros de uma sociedade historicamente dada" $" 10$.

Quase como uma sequência lógica da sua tese de livre docência, Saffioti publicou, em 1978, a obra Emprego Doméstico e Capitalismo ${ }^{11}$. Nesse livro, a autora desenvolveu a ideia de como o capitalismo se expandiu sem que houvesse um avanço qualitativo rumo à emancipação feminina. ${ }^{12}$ Ela também destacou a importância do trabalho doméstico para a manutenção do sistema capitalista, na medida em que atua de forma não capitalista no interior das formações sociais dominadas por esse modo de produção, o que não impede que o resultado do trabalho doméstico seja absolutamente imprescindível à reprodução do capital. ${ }^{13}$

As autoras Danièle Kergoat e Helena Hirata, respectivamente socióloga e filósofa, são referências nos estudos de gênero e do trabalho. Nos vários trabalhos que já publicaram, em conjunto ou separadamente, ambas introduziram e exploraram a importante noção da "divisão sexual do trabalho"14. Segundo essa ideia, a separação entre trabalhos ditos femininos e masculinos e a hierarquização desses tipos de trabalhos, sendo que os trabalhos masculinos ocupam uma posição hierárquica superior, são frutos de uma construção social.

Dentro desse contexto, as pesquisadoras analisam recorrentemente o trabalho doméstico que é social e historicamente atribuído às mulheres. O trabalho realizado dentro do domicílio é considerado como trabalho reprodutivo no modelo de produção capitalista e, portanto, inferiorizado e sem atribuição de valor. Nos últimos anos, Kergoat e Hirata têm sido

8 GONÇALVES, Renata. Prefácio. In: SAFFIOTI, Heleieth Iara Bongiovani. A mulher na sociedade de classes: mito e realidade. 3. ed. São Paulo: Expressão Popular, 2013.

Ibid., p. 17.

Ibid., loc. cit.

11 SAFFIOTI, Heleieth Iara Bongiovani. Emprego doméstico e capitalismo. Petrópolis: Vozes, 1978.

12 GONÇALVES, op. cit., p. 24.

13 SAFFIOTI, op. cit., p. 195.

14 Cf. KERGOAT, Danièle. Divisão sexual do trabalho e relações sociais de sexo. In: HIRATA, Helena et al. (Org.). Dicionário Crítico do Feminismo. São Paulo: Unesp, 2009, p. 67-75 e HIRATA, Helena; KERGOAT, Danièle. Novas configurações da divisão sexual do trabalho. Cadernos de Pesquisa. v. 37, n. 132, p. 595-609, set./dez.2007, p. 599. 
pioneiras no desenvolvimento de uma importante linha de estudos sobre uma das facetas ${ }^{15}$ do trabalho doméstico, que é o estudo do trabalho de cuidado ou o care work $^{16}$.

A antropóloga Jurema Brites também contribuiu significativamente na pesquisa sobre emprego doméstico no Brasil. Em sua tese de doutorado Afeto, Desigualdade e Rebeldia: bastidores do serviço doméstico ${ }^{17}$, ela desenvolveu pesquisa a partir das descrições da vida cotidiana das empregadas domésticas na cidade de Vitória, Espírito Santo, tanto no trabalho quanto onde elas moram. A autora afastou, sobretudo, a ideia de conformismo das empregadas domésticas com as condições de trabalho e demonstrou estratégias infrapolíticas que elas encontram para reverter esse quadro.

Mais significativo para o desenvolvimento do presente trabalho, contudo, foi o texto de autoria de Jurema Brites, denominado Trabalho doméstico: questões, leituras e políticas $^{18}$, no qual foi realizada importante revisão da literatura sobre o tema no Brasil. Além disso, a pesquisadora destacou o lugar social de onde são recrutadas as trabalhadoras domésticas remuneradas, como uma atividade altamente feminizada e fruto de um entrecruzamento de desigualdades. ${ }^{19}$ Segundo a autora, “[...] no trabalho doméstico, a força de trabalho é recrutada entre mulheres, as quais geralmente provêm daquelas camadas mais pobres e com índices menores de escolaridade, características sobrepostas por uma forte marca de racialização" ${ }^{20}$.

Nesse contexto, o livro da historiadora Lorena Teles, Libertas entre $\operatorname{sobrados}^{21}$, foi essencial na presente pesquisa, uma vez que ela faz análise minuciosa sobre a trajetória da mulher negra de origem africana, escrava ou filha de escrava, em São Paulo, no fim do século XIX e início do século XX. A grande maioria dessas mulheres passou de

15 A afirmação de que o trabalho de cuidado é uma das facetas do trabalho doméstico não exclui a hipótese recorrente de que ele seja realizado fora do ambiente doméstico, como em asilos para idosos ou creches infantis, por exemplo.

16 "Cuidado, solicitude, atenção ao outro, todas essas palavras ou expressões são traduções aproximadas do termo inglês care. O care é dificilmente traduzível porque polissêmico. Cuidar do outro, preocupar-se, estar atento às suas necessidades, todos esses diferentes significados relacionados tanto à atitude quanto à ação, estão presentes na definição do care. Este, ademais, pode ser considerado simultaneamente enquanto prática e enquanto atitude, ou disposição moral. Autoras francesas (PAPERMAN; LAUGIER, 2005; MOLINIER; LAUGIER; PAPERMAN, 2009) preferem utilizar o termo inglês, considerando que sua tradução literal, soin, tem uma conotação terapêutica que seria redutora dos sentidos que analiticamente se quer reter" (cf. HIRATA, Helena; GUIMARÃES, Nadya Araujo (Org.). Cuidado e cuidadoras: as várias facetas do trabalho do care. São Paulo: Atlas, 2012, p. 01.

17 BRITES, Jurema. Afeto, Desigualdade e Rebeldia: bastidores do serviço doméstico. 2000. Tese (Doutorado em Antropologia Social) - Universidade Federal do Rio Grande do Sul, Porto Alegre, 2000.

18 Ibid., p. 421-451.

19 Ibid., p. 426.

20 Ibid., p. 429.

21 TELES, Lorena Feres da Silva. Libertas Entre Sobrados: Mulheres Negras e Trabalho Doméstico em São Paulo (1880-1920). São Paulo: Alameda, 2014. 
escrava para empregada doméstica, o que explica, mas não justifica, o tratamento discriminatório dispensado às mulheres que exercem essa profissão. Essa análise histórica também demonstra a influência que o passado colonial escravista exerce na acentuação das desigualdades entre mulheres e homens negros das mulheres e homens brancos, evidenciando, como pretende Brites, o "[...] lugar social [em] que se dá o maior recrutamento de trabalhadoras e onde também outras desigualdades se interseccionam"22.

Conclui-se, portanto, que a discriminação sofrida pelas empregadas domésticas apenas pode ser apreendida a partir do cruzamento de três marcadores de subordinação, que são típicos das daquelas que exercem essa profissão no Brasil: mulheres, negras e pobres. A necessidade deste estudo conjunto partiu da influência da ideia de interseccionalidade, conceito cunhado pela jurista norte-americana Kimberlé Crenshaw, ou consubstancialidade das relações sociais, de autoria da francesa Danièle Kergoat. Apesar de distintos, ambos os conceitos ressaltam a necessidade do estudo de diferentes formas de subordinação em conjunto para que nenhum tipo de discriminação seja obscurecido.

A análise interseccional também é necessária quando se observa o emprego doméstico em outras partes do mundo. Os fluxos migratórios internacionais para o exercício do emprego doméstico têm se tornado cada vez mais intensos e, nesses casos, o gênero, a classe social, a raça, em alguns casos, interseccionam com a nacionalidade como fatores que contribuem para a discriminação dessas trabalhadoras nos países de destino. As mulheres que assumem o protagonismo desse movimento migratório global foram centrais no estudo "Love and Gold" ${ }^{, 23}$ desenvolvido por Arlie Hoschishild, tanto do ponto de vista do cuidado e amor que são exportados para o Norte, quanto da carência experimentada pelas crianças do Sul.

Cita-se, por fim, a relevante tese de doutorado do sociólogo Joaze BernadinoCosta sobre os sindicatos das trabalhadoras domésticas no Brasil ${ }^{24}$, que foi desenvolvida a partir das vozes das próprias trabalhadoras "[...] num esforço de pensar e falar com e a partir das trabalhadoras domésticas" ${ }^{25}$. De início, Bernadino-Costa apresentou sua intenção, que foi questionar a interpretação hegemônica das relações sociais brasileiras que insiste na

22 BRITES, Jurema. Trabalho doméstico: questões, leituras e políticas. Cadernos de Pesquisa, v. 43, n. 149 , 2013, p. 421-451.

23 HOCHSCHILD, Arlie R. Love and Gold. In: EHRENREICH, Barbara; HOCHSCHILD, Arlie R. (Ed.). Global Woman: Nannies, Maids, and Sex Workers in the New Economy. New York: Metropolitan Books, 2003, p. 19.

24 BERNARDINO-COSTA, Joaze. Sindicatos das trabalhadoras domésticas no Brasil: teorias da descolonização e saberes subalternos. 2007. Tese (Doutorado em Sociologia) - Universidade de Brasília, Brasília, 2007.

25 Ibid., p. 08. 
complementariedade e harmonia entre pobres e ricos, negros e brancos. Ele acrescentou que o trabalho doméstico, escravo ou livre, é um dos maiores exemplos desse "caráter singular das relações sociais brasileiras",26.

Segundo o autor, a mencionada interpretação hegemônica e harmônica foi sintetizada por Gilberto Freyre $^{27}$, em 1933, segundo o qual a casa-grande e a senzala representam a unidade de entendimento do Brasil:

[...] sua historiografia, fortemente baseada na história íntima da família brasileira, defende que inauguramos um sistema social democrático tanto do ponto de vista econômico quanto racial, aberto à mobilidade social dos negros e pobres. Todavia, a ascensão social se daria preferencialmente pela miscigenação, cujo produto seria o/a chamado/a mulato/a. A miscigenação, por sua vez, ocorreria principalmente através da escrava de casa: a mucama. Neste sistema social, a escrava da casa seria hierarquicamente superior às escravas da senzala e, consequentemente, desfrutaria de alguns privilégios. Do relacionamento íntimo entre família patriarcal e escrava redundaria o mulato, o filho bastardo do senhor de engenho e da escrava da casa, que, ao invés de se revoltar contra seu pai, por não ser reconhecido como filho legítimo, imitava-o, através da assimilação de valores europeus (Cf. Freyre, 1990). O resultado desta fórmula é, segundo a narrativa do autor em questão, a chamada democracia racial, ou seja, a raça deixa de ser um elemento significativo para a ascensão social das pessoas, sendo decisiva a sua competência, mensurada pelo grau de proximidade aos valores europeus. ${ }^{28}$

Ele conclui dizendo que o posicionamento de Gilberto Freyre, além de reforçar a harmonia entre polos antagônicos da sociedade brasileira, sanciona negativamente qualquer interpretação da realidade brasileira baseada no conflito. ${ }^{29}$ Bernardino-Costa elegeu, então, os sindicatos das trabalhadoras domésticas com a intenção de "[...] entender como aqueles que estão em uma posição subalterna percebem as relações sociais" ${ }^{30}$, que, ressaltou o pesquisador, não são relações entre iguais, mas sim hierárquicas.

O presente trabalho, portanto, foi desenvolvido a partir da influência das obras mencionadas acima e de várias outras decorrentes delas para procurar entender, no decorrer de três capítulos, a resposta à seguinte indagação: o que verdadeiramente está por trás da privação de direitos das empregadas domésticas no Brasil?

26 BERNARDINO-COSTA, Joaze. Sindicatos das trabalhadoras domésticas no Brasil: teorias da descolonização e saberes subalternos. 2007. Tese (Doutorado em Sociologia) - Universidade de Brasília, Brasília, 2007.

27 FREYRE, Gilberto. Casa Grande \& Senzala: formação da família brasileira sob o regime da economia patriarcal. 28. ed. Rio de Janeiro: Record, 1992.

28 Ibid., p. 09.

29 Ibid.

30 Ibid., p. 10. 
O primeiro capítulo buscará traçar o perfil das empregadas domésticas no país, com base na última Pesquisa Nacional por Amostra de Domicílios do Instituto Brasileiro de Geografia e Estatística (PNAD/IBGE), realizada entre os anos de 2004 e 2014. Os dados da pesquisa evidenciam um total de 5,9 milhões de empregadas domésticas no Brasil no ano de 2014, das quais a maioria é composta por mulheres negras. Notou-se, ainda, um envelhecimento da categoria, além da continuidade da baixa escolaridade. Todos esses fatores contribuem para a desvalorização do emprego doméstico com os consequentes alto nível de informalidade e baixa remuneração

Esse perfil de gênero, classe e raça das empregadas domésticas no Brasil apenas poderá ser apreendido a partir das ideias da divisão sexual do trabalho, da bipolarização do trabalho feminino e da herança escravista do emprego doméstico. Essas ideias deverão ser tratadas de forma conjunta, interligadas, mas não hierarquizadas, conforme indicado pela teoria da interseccionalidade, para que se possa avaliar a real dimensão da discriminação e da privação de direitos das empregadas domésticas.

Após o desenho do sujeito das normas trabalhistas que tratam do emprego doméstico, no segundo capítulo será abordada a história da regulamentação da profissão. A institucionalização da discriminação perpetrada contra as empregadas domésticas ficará evidente a partir da análise do ordenamento jurídico nacional, que, por tantos anos, privou essas trabalhadoras do gozo de vários direitos trabalhistas.

A análise seguirá do período que antecedeu a promulgação da Consolidação das Leis Trabalhistas (CLT), em 1943, até a promulgação da atual Lei Complementar $n^{\circ} 150$ de 2015 (LC 150/2015). Pretende-se demonstrar que, há pelo menos setenta anos, as justificativas para afastar a equiparação plena de direitos das domésticas com as demais trabalhadoras e trabalhadores revestem-se sob a forma do argumento econômico, sempre utilizado para beneficiar os empregadores, como se fosse um princípio protetivo às avessas ${ }^{31}$. A CLT excluiu do seu rol protetivo "[...] aqueles que prestam serviço de natureza não econômica"; a Lei $\mathrm{n}^{\mathrm{o}}$ 5.859/72, que estendeu apenas três direitos à categoria, cunhou a expressão finalidade não lucrativa, referindo-se à atividade desempenhada pelas domésticas; a Constituição Federal manteve a exclusão dessa classe de trabalhadoras cuja atividade “[...]

31 FREITAS JÚNIOR, Antônio Rodrigues de; KOURY, Ana Beatriz Costa. Domestic employment in Brazil: legal outcomes after the passing of Constitutional Amendment No. 72 of 2013. Artigo apresentado na 4th Regulating for Decent Work Conference on "Developing and Implementing Policies for a Better Future at Work". Genebra, Suíça: OIT, 8-10 jul. 2015. 
não constituía fator de produção na atividade capitalista"32 e a EC 72/2013 não foi capaz de promover a equiparação plena, muito em razão dos alegados elevados encargos financeiros que os empregadores domésticos teriam que suportar. ${ }^{33}$

Ainda no final do segundo capítulo, passa-se à análise da LC 150/2015 naquilo que se diferencia dos direitos dos trabalhadores "urbanos e rurais", com ênfase nos seguintes itens: habitualidade para configuração do vínculo empregatício doméstico - que manteve à margem da proteção trabalhista milhares de diaristas que prestam serviço por até dois dias por semana, incorrendo em verdadeira inconstitucionalidade -, jornada de trabalho, fiscalização, impenhorabilidade do bem de família, hipóteses especiais e multa no caso de justa causa e, por fim, Simples do Empregado Doméstico. Será possível inferir que a verdadeira sonegação de direitos não veio com a não equiparação total de direitos pela Emenda Constitucional $n^{\circ}$ 72 , mas principalmente com a sua regulamentação.

Por fim, pretende-se demonstrar no terceiro e último capítulo a importância da articulação e organização das empregadas domésticas para a concessão de direitos trabalhistas ao longo dos anos. Além da falta de vontade política, a organização das empregadas domésticas enfrentou alguns obstáculos específicos, como a dificuldade do reconhecimento de uma identidade profissional, agravada por um isolamento, que é típico da profissão, e a discriminação interseccional.

A privação de direitos às empregadas domésticas perpetua-se por muito tempo, mas não por falta de luta de organizações representativas da categoria, cujas histórias serão brevemente relatadas, a saber: Associação das Empregadas Domésticas em Santos, Sindicato das Trabalhadoras Domésticas de Campinas, Sindicato das Trabalhadoras Domésticas do Estado da Bahia e Federação Nacional das Trabalhadoras Domésticas (FENATRAD). Pretende-se demonstrar como a articulação da classe para a aprovação da Convenção 189 da OIT impulsionou as últimas mudanças legislativas, bem como analisar a atual situação da organização relativamente à legislação vigente.

Espera-se que a leitura do presente trabalho seja permeada pelas ideias centrais constantes nos seus três capítulos, respectivamente: 1- o perfil de gênero, raça e classe das empregadas domésticas influencia diretamente na posição inferiorizada que a categoria

32 COSTA, Beatriz Rezende Marques. Trabalho Doméstico. Câmara dos Deputados, Diretoria Legislativa, Consultoria Legislativa. Brasília, abr. 2013.

33 FREITAS JÚNIOR, Antônio Rodrigues de; KOURY, Ana Beatriz Costa. Domestic employment in Brazil: legal outcomes after the passing of Constitutional Amendment No. 72 of 2013. Artigo apresentado na 4th Regulating for Decent Work Conference on "Developing and Implementing Policies for a Better Future at Work”. Genebra, Suíça: OIT, 8-10 jul. 2015. 
assume na sociedade brasileira e, consequentemente, reflete na não concessão de direitos trabalhistas; 2- não há justificativa para a privação de direitos às empregadas domésticas, e o argumento econômico que vem sendo utilizado deve, imediatamente, ser afastado; e 3- a morosidade na concessão de novos direitos não foi por falta de luta da categoria, e as vozes das empregadas não podem mais ser abafadas. 


\title{
CONSIDERAÇÕES FINAIS
}

\begin{abstract}
O mundo do trabalho é a dimensão mais importante da vida social, tanto do ponto de vista da produção de bens e serviços para as coletividades, como, também, do ponto de vista da autonomia econômica e de realização individual. Ocupando lugar central na organização de nossas sociedades, reproduz suas injustiças e desigualdades e gera e reforça outras tantas. ${ }^{451}$
\end{abstract}

A existência do emprego doméstico, por ser fonte de tantas injustiças sociais, é frequentemente questionada: devemos, afinal, defender o fim desse trabalho remunerado? A resposta simplista que vem à cabeça é que, se todos os direitos sociais foram estendidos a essa categoria, se as empregadas domésticas forem tratadas de forma justa e devidamente remuneradas, não há por que defender o seu fim.

Todavia, o estudo para o presente trabalho demonstrou que o emprego doméstico envolve outras questões de dimensões históricas, sociológicas e até psicológicas que não comportam uma resposta simples e com o viés de quem sempre se beneficiou do trabalho doméstico remunerado. Talvez a resposta possa até ser favorável à continuidade da existência do emprego doméstico, mas se, e somente se, sua existência não implicar na reprodução nociva da divisão sexual, racial, social e Norte/Sul do trabalho. O trabalho doméstico não pode continuar sendo desvalorizado e considerado um subemprego porque é exercido por uma maioria e mulheres, negras, pobres e migrantes. E, da mesma forma, não pode ser a única porta de entrada dessas mulheres para o mercado de trabalho porque é uma atividade de menor valor.

Passou da hora de o emprego doméstico ser tratado como uma profissão como todas as outras e que não seja regulamentado tendo por parâmetro o perfil daquelas que exercem essa função. $\mathrm{O}$ ordenamento jurídico, portanto, não pode relegar o emprego doméstico a um segundo plano, como se não fosse um trabalho como qualquer outro. Durante anos, a legislação nacional perpetrou a discriminação contra as empregadas domésticas sob o pretexto de essa atividade não ser considerada econômica ou não produzir lucro, a partir de visões extremamente restritas e distorcidas de atividade econômica e produção de lucro. Sabese que tal argumento não pode prevalecer porque, em primeiro lugar, o emprego doméstico desempenha importante papel na economia do país, uma vez que desonera milhares de outros trabalhadores das atividades domésticas, que, por sua vez, ficam disponíveis e dedicam várias horas para o trabalho dito propriamente lucrativo nas empresas empregadoras. Além disso, o

451 PINHEIRO, Luana Simões et al. Nota técnica - Mulheres e trabalho: breve análise do período 2004-2014. n. 24. Brasília: Ipea, 2016, p. 27. 
mesmo racional de "atividade não econômica" não foi utilizado para privar direitos de outros trabalhadores de "instituições de beneficência, as associações recreativas ou outras instituições sem fins lucrativos", conforme art. $2^{\circ}$, parágrafo segundo, da CLT.

Mesmo os avanços legislativos recentes, notadamente a EC 72/2013, não foram suficientes para corrigir a injustiça histórica perpetrada contra as empregadas domésticas. Além de não promover a equiparação plena das domésticas com os demais trabalhadores, a LC 150/2013, que regulamentou a matéria, acabou por excluir da proteção social todas aquelas que trabalham no ambiente doméstico por até dois dias por semana.

Deve-se manter em mente que qualquer discurso que justifique a discriminação das trabalhadoras domésticas quando da elaboração das leis para concessão de direitos tem como ponto de partida um "lugar de fala" que se beneficia da exploração do trabalho doméstico, claramente negligenciando as demandas das próprias trabalhadoras. $\mathrm{O}$ ponto de vista das trabalhadoras deve ser cada vez mais central nas discussões sobre a regulamentação do emprego doméstico, motivo pelo qual o presente trabalho é encerrado com o discurso de representante da categoria que responde à pergunta apresentada no início dessa sessão e expõe o que elas esperam do futuro dessa profissão:

De certa forma, o debate sobre melhoria de vida para as trabalhadoras domésticas gera polêmica. No próprio campo progressista há comentários do tipo: "Por que qualificar as trabalhadoras domésticas? Essa profissão tem que acabar!" Nós acreditamos que é válida toda atuação profissional que tenha por base a luta pela sobrevivência, não temos vergonha de sermos trabalhadoras domésticas, mas é importante que a sociedade reconheça o valor social dessa categoria profissional e sua importância para economia brasileira e mundial. O correto não é acabar com essa modalidade de trabalho, mas, sim, contribuir para que as profissionais tenham autoestima $\mathrm{e}$ garantia de condições dignas de atuação, pois a atividade ainda carrega características e marcas da escravidão. ${ }^{452}$

${ }^{452}$ OLIVEIRA, Creuza. Luta e resistência para a valorização do trabalho doméstico. In: RIBEIRO, Matilde (Coord.). As políticas de igualdade racial: reflexões e perspectivas. São Paulo: Perseu Abramo, 2012, p. 94. 


\section{REFERÊNCIAS}

ALCOFF, Linda Martín. The Problem of Speaking for Others. Disponível em: $<$ http://www.alcoff.com/content/speaothers.html>. Acesso em: 06 maio 2017.

ALMEIDA, Táli Pires de. Migração internacional feminina: trajetórias entre Bolívia, Paraguai, Peru e Brasil. In: CARNEIRO, Maria Luiza Tucci; HIRANO, Sedi (Org.). Histórias migrantes: um mosaico de nacionalidades e múltiplas culturas. São Paulo: Humanitas; FAPESP, 2014. p. 205-232.

ANTUNES, Ricardo. Os Sentidos do Trabalho: ensaios sobre a afirmação e a negação do trabalho. São Paulo: Boitempo, 1999.

Popular, 2004.

(Org.). A dialética do trabalho: escritos de Marx e Engels. São Paulo: Expressão

BARROS, Veronica Altef. Qualificação profissional do trabalhador doméstico no Brasil: análise na perspectiva do trabalho decente. 2013. Tese (Doutorado em Direito) Universidade de São Paulo, São Paulo, 2013.

BEAUVOIR, Simone de. Le deuxième sexe II. Paris: Gallimard, 1976.

BERNARDINO-COSTA, Joaze. Sindicatos das trabalhadoras domésticas no Brasil: teorias da descolonização e saberes subalternos. 2007. Tese (Doutorado em Sociologia) Universidade de Brasília, Brasília, 2007.

BRASIL. Câmara dos Deputados. Mandado de Segurança Coletivo $n^{\circ}$ 132, de 2006. Convenção sobre o Trabalho Decente para as Trabalhadoras e os Trabalhadores Domésticos $\left(n^{\circ} 189\right)$ e respectiva Recomendação (n $\left.n^{\circ} 201\right)$, da Organização Internacional do Trabalho. Brasília: 07 abr. 2016. Disponível em:

$<$ http://www.camara.gov.br/proposicoesWeb/fichadetramitacao?idProposicao=2081863>. Acesso em: 24 fev. 2017.

. Câmara dos Deputados. Proposta de Emenda à Constituição 478, de 14 de abril de 2010. Revoga o parágrafo único do art. $7^{\circ}$ da Constituição Federal, para estabelecer a igualdade de direitos trabalhistas entre os empregados domésticos e os demais trabalhadores urbanos e rurais. Brasília, 14 abr. 2010. Disponível em:

$<$ http://www.camara.gov.br/proposicoesWeb/prop_mostrarintegra;jsessionid=59E67888AAC BE63C9DBB127D5624105A.node1? codteor $=755258 \&$ filename $=\mathrm{PEC}+478 / 2010>$. Acesso em: 18 out. 2013.

BRASIL. Ministério do Trabalho. Informações Gerais. Brasília, 2017. Disponível em: $<$ http://www.mtecbo.gov.br/cbosite/pages/informacoesGerais.jsf $>$. Acesso em: 15 jun. 2016.

BRASIL. Ministério do Trabalho. Secretaria de Inspeção do Trabalho. Instrução Normativa $n^{o}$ 110, de 06.08.2014. Brasília: DOU, 07 ago. 2014. Disponível em:

$<$ http://www.normaslegais.com.br/legislacao/instrucao-normativa-SIT-110-2014.htm>. Acesso em: 21 mar. 2017.

BRASIL. Ministério do Trabalho. Secretaria de Relações do Trabalho. Instrução Normativa $n^{o} 01$ de 12.10.1988. Brasília: DOU, 21 out. 1988. Disponível em: 
$<$ http://www.normaslegais.com.br/legislacao/trabalhista/instrucaonormativasrt01_1988.htm>. Acesso em: 25 jan. 2017.

BRASIL. Presidência da República. Constituição da República Federativa do Brasil de 1988. Brasília, 5 de outubro de 1988.

BRASIL. Presidência da República. Decreto $n^{\circ} 3.361$, de 10 de fevereiro de 2000. Regulamenta dispositivos da Lei $\mathrm{n}^{0}$ 5.859, de 11 de dezembro de 1972, que dispõe sobre a profissão de empregado doméstico, para facultar o acesso do empregado doméstico ao Fundo de Garantia do Tempo de Serviço - FGTS e ao Programa do Seguro-Desemprego. Brasília: DOU, 11 fev. 2000.

BRASIL. Presidência da República. Decreto $n^{\circ} 71.885$, de 26 de fevereiro de 1973. Aprova o Regulamento da Lei número 5.859, de dezembro de 1972, que dispõe sobre a profissão de empregado doméstico, e dá outras providências. Brasília: DOU, 09 mar. 1973.

BRASIL. Presidência da República. Decreto $n^{\circ}$ 95.247, de 17 de novembro de 1987. Regulamenta a Lei ${ }^{\circ} 7.418$, de 16 de dezembro de 1985, que institui o Vale-Transporte, com a alteração da Lei n 7.619, de 30 de setembro de 1987. Brasília: DOU, 18 nov. 1987.

BRASIL. Presidência da República. Decreto-Lei $n^{\circ}$ 5.452, de $1^{\circ}$ de maio de 1943. Aprova a Consolidação das Leis do Trabalho. Rio de Janeiro: DOU, 08 ago. 1943, sem destaque no original.

BRASIL. Presidência da República. Lei Complementar $n^{\circ} 150$, de $1^{\circ}$ de junho de 2015. Dispõe sobre o contrato de trabalho doméstico; altera as Leis no 8.212, de 24 de julho de 1991, no 8.213, de 24 de julho de 1991, e no 11.196, de 21 de novembro de 2005; revoga o inciso I do art. 30 da Lei no 8.009, de 29 de março de 1990, o art. 36 da Lei no 8.213, de 24 de julho de 1991, a Lei $\mathrm{n}^{\circ}$ 5.859, de 11 de dezembro de 1972, e o inciso VII do art. 12 da Lei no 9.250, de 26 de dezembro 1995; e dá outras providências. Brasília: DOU, 02 jun. 2015.

BRASIL. Presidência da República. Lei $n^{\circ} 10.208$, de 23 de março de 2001. Acresce dispositivos à Lei $\mathrm{n}^{\circ} 5.859$, de 11 de dezembro de 1972, que dispõe sobre a profissão de empregado doméstico, para facultar o acesso ao Fundo de Garantia do Tempo de Serviço FGTS e ao seguro-desemprego. Brasília: DOU, 24 mar. 2001 (edição extra).

BRASIL. Presidência da República. Lei $n^{\circ} 11.324$, de 19 de julho de 2006. Altera dispositivos das Leis nos 9.250, de 26 de dezembro de 1995, 8.212, de 24 de julho de 1991, 8.213, de 24 de julho de 1991, e 5.859, de 11 de dezembro de 1972; e revoga dispositivo da Lei no 605, de 5 de janeiro de 1949. Brasília: DOU, 20 jul. 2006.

BRASIL. Presidência da República. Lei $n^{\circ} 11.340$, de 7 de agosto de 2006. Cria mecanismos para coibir a violência doméstica e familiar contra a mulher, nos termos do § 80 do art. 226 da Constituição Federal, da Convenção sobre a Eliminação de Todas as Formas de Discriminação contra as Mulheres e da Convenção Interamericana para Prevenir, Punir e Erradicar a Violência contra a Mulher; dispõe sobre a criação dos Juizados de Violência Doméstica e Familiar contra a Mulher; altera o Código de Processo Penal, o Código Penal e a Lei de Execução Penal; e dá outras providências. Brasília: DOU, 08 ago. 2006. Disponível em: $<$ http://www.planalto.gov.br/ccivil_03/_ato2004-2006/2006/lei/111340.htm>. Acesso em: 26 jun. 2017. 
BRASIL. Presidência da República. Lei $n^{\circ} 5.316$, de 14 de setembro de 1967. Integra o seguro de acidentes do trabalho na previdência social, e dá outras providências. Brasília: DOU, 18 set. 1967, retificado em 22 set. 1967, retificado em 27 set. 1967 e republicado em 08 abr. 1974.

BRASIL. Presidência da República. Lei $n^{\circ}$ 5.859, de 11 de dezembro de 1972. Dispõe sobre a profissão de empregado doméstico e dá outras providências. Brasília: DOU, 12 dez. 1972.

BRASIL. Presidência da República. Lei $n^{\circ} 7.787$, de 30 de junho de 1989. Dispõe sobre alterações na legislação de custeio da Previdência Social e dá outras providências. Brasília: DOU, 30 jul. 1989.

BRASIL. Presidência da República. Lei $n^{\circ}$ 8.009, de 29 de março de 1990. Dispõe sobre a impenhorabilidade do bem de família. Brasília: DOU, 30 mar. 1990.

BRASIL. Presidência da República. Mensagem $n^{\circ}$ 197, de $1^{\circ}$ de junho de 2015. Brasília: DOU, 02 jun. 2015. Disponível em: <http://www.planalto.gov.br/ccivil_03/_ato20152018/2015/Msg/VEP-197.htm>. Acesso em: 26 mar. 2017.

BRASIL. Previdência Social. Tipos de filiação. Brasília, 17 abr. 2013. Disponível em: $<$ http://www.previdencia.gov.br/servicos-ao-cidadao/informacoes-gerais/tipos-filiacao/>. Acesso em: 03 dez. 2016.

BRASIL. Senado Federal. Assembléia Nacional Constituinte - Ata de Comissões. Brasília, 07 abr. 1987. Disponível em: <http://www.senado.leg.br/publicacoes/anais/constituinte/7a SUBCOMISSÃO DOS DIREITOS DOS TRABALHADORES.pdf $>$. Acesso em: 12 jan. 2017.

BRASIL. Senado Federal. Atividade Legislativa. Substitutivo da Câmara dos Deputados $n^{\circ} 5$, de 2015, AO PLS n ${ }^{\circ} 224$, de 2013 (complementar) - Lei dos Empregados Domésticos. Dispõe sobre o contrato de trabalho doméstico; altera as Leis $\mathrm{n}^{\circ} 8.212$, de 24 de julho de $1991, \mathrm{n}^{\mathrm{o}}$ 8.213 , de 24 de julho de 1991, e Lei $n^{\circ} 11.196$, de 21 de novembro de 2005; e revoga o inciso I do art. $3^{\circ}$ da Lei $n^{\circ} 8.009$, de 29 de março de 1990 e a Lei ${ }^{\circ} 5.859$, de 11 de dezembro de 1972. Disponível em: https://www25.senado.leg.br/web/atividade/materias/-/materia/120159. Acesso em: 17 mar. 2017.

BRASIL. Superior Tribunal de Justiça. Súmula $n^{\circ} 1$. Julgamento: 25 abr. 1990. Órgão Julgador: Segunda Seção. Publicação: DJ, 02 maio 1990.

BRASIL. Tribunal Superior do Trabalho. Conteúdo Web. Brasília, 07 jan. 2005. Disponível em:

http://www.tst.jus.br/home?p_p_id $=15 \& p \_p \_l i f e c y c l e=0 \& p \_p \_s t a t e=$ maximized\&p_p_mode

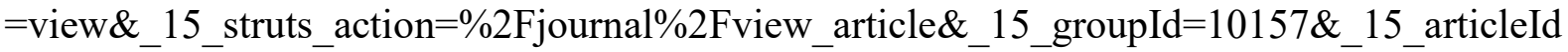
$=250079 \& \_15 \_$version=1.0. Acesso em: 04 fev. 2016 .

BRASIL. Tribunal Superior do Trabalho. Órgão Julgador: Agravo de Instrumento em Recurso de Revista $n^{\circ}$ 1163-62.2011.5.02.0482. Relator: Ministro Douglas Alencar Rodrigues. Julgamento: 04 fev. 2015. Órgão Julgador: Sétima Turma. Publicação: DEJT, 06 fev. 2015.

BRASIL. Tribunal Superior do Trabalho. Recurso de Revista $n^{\circ} 101200-63.2009 .5 .05 .0101$. Relator: Ministro Guilherme Augusto Caputo Bastos. Julgamento: 19 fev. 2014. Órgão Julgador: Quinta Turma. Publicação: DEJT, 07 mar. 2014. 
BRASIL. Tribunal Superior do Trabalho. Recurso de Revista $n^{\circ}$ 52.776/2002-900-16-00.1. Relator: Ministro Emmanoel Pereira. Julgamento: 07 jan. 2005. Órgão Julgador: Primeira Turma. Publicação: DJ, 18 fev. 2005. Disponível em: <http://brs02.tst.gov.br/cgi-bin/nphbrs?s1=3833581.nia. $\& u=/ B r s / i t 01 . h t m l \& p=1 \& l=1 \& d=b l n k \& f=g \& r=1>$. Acesso em: 05 fev. 2017.

BRASIL. Tribunal Superior do Trabalho. Súmula $n^{\circ} 118$. Jornada de Trabalho. Horas Extras (mantida). Brasília: DJ, 19, 20 e 21 nov. 2003.

BRASIL. Tribunal Superior do Trabalho. Súmula $n^{\circ} 444$. Jornada de Trabalho. Lei. Escala de 12 por 36. Validade. Brasília: DEJT, 25, 26 e 27 set. 2012, 26 nov. 2012.

BRITES, Jurema. Trabalho doméstico: questões, leituras e políticas. Cadernos de Pesquisa, v. 43, n. 149, p. 421-451, 2013.

. Afeto, Desigualdade e Rebeldia: bastidores do serviço doméstico. 2000. Tese

(Doutorado em Antropologia Social) - Universidade Federal do Rio Grande do Sul, Porto Alegre, 2000.

CALIXTRE, André; VAZ, Fábio. Nota técnica - Pnad 2014: breves análises. n. 22. Brasília: Ipea, 2015.

CASAGRANDE, Cássio. Trabalho doméstico e discriminação. Boletim CEDES, set. 2008. Disponível em: $<$ http://www.cis.puc-rio.br/cedes/banco artigos/Direito e Trabalho/trabalho doméstico e discriminação.pdf>. Acesso em: 17 out. 2013.

CORTEZ, Julpiano Chaves. A lei dos empregados domésticos e os direitos trabalhistas: lei complementar n. 150/2015. São Paulo: LTr, 2016.

COSTA, Beatriz Rezende Marques. Trabalho Doméstico. Câmara dos Deputados, Diretoria Legislativa, Consultoria Legislativa. Brasília, abr. 2013. Disponível em:

$<$ http://www2.camara.gov.br/documentos-e-

pesquisa/fiquePorDentro/temas/empregado_domestico_seg_ed/texto-base-da-consultorialegislativa $>$. Acesso em: 17 out. 2013.

COSTA, Emília Viotti da. Da Senzala à Colônia. 5. ed. São Paulo: UNESP, 2010.

CRENSHAW, Kimberlé W. Documento para o encontro de especialistas em aspectos da discriminação racial relativos ao gênero. Revista Estudos Feministas, ano 10, $1^{\circ}$ sem., p. 171188, 2002.

DELGADO, Maurício Godinho. Curso de Direito do Trabalho. 10. ed. São Paulo: LTr, 2011.

FAUSTO, Boris. História concisa do Brasil. 2. ed. São Paulo: Edusp, 2006.

FENATRAD. Institucional. Salvador: Fenatrad, 2017. Disponível em:

$<\mathrm{http}$ ://www.fenatrad.org.br/site/?page_id=112>. Acesso em: 01 maio 2017.

FREITAS JÚNIOR, Antônio Rodrigues de. Efetivação dos direitos sociais como condição da Democracia. In: CORREIA, Marcus Orione Gonçalves (Org.). Curso de Direito do Trabalho. v. 1: teoria geral do direito do trabalho. São Paulo: LTr, 2007. p. 41-62. 
; KOURY, Ana Beatriz Costa. Domestic employment in Brazil: legal outcomes after the passing of Constitutional Amendment No. 72 of 2013. Artigo apresentado na 4th Regulating for Decent Work Conference on "Developing and Implementing Policies for a Better Future at Work”. Genebra, Suíça: OIT, 8-10 jul. 2015.

FREYRE, Gilberto. Casa Grande \& Senzala: formação da família brasileira sob o regime da economia patriarcal. 28. ed. Rio de Janeiro: Record, 1992.

GOMES, Flávio dos Santos. Quilombos: Sonhando com a terra, construindo a cidadania. In: PINSKY, Jaime; PINSKY, Carla Bassanezi (Org.). História da Cidadania. 3. ed. São Paulo: Contexto, 2005. p. 447- 468.

GONÇALVES, Renata. Prefácio. In: SAFFIOTI, Heleieth. A mulher na sociedade de classes: mito e realidade. 3. ed. São Paulo: Expressão Popular, 2013.

HIRATA, Helena. Nova divisão sexual do trabalho? Um olhar voltado para a empresa e a sociedade. São Paulo: Boitempo, 2002.

; KERGOAT, Danièle. Novas configurações da divisão sexual do trabalho. Cadernos de Pesquisa, v. 37, n. 132, p. 595-609, set./dez. 2007.

; GUIMARÃES, Nadya Araujo (Org.). Cuidado e cuidadoras: as várias facetas do trabalho do care. São Paulo: Atlas, 2012.

Gênero, classe e raça: Interseccionalidade e consubstancialidade das relações sociais. Tempo Social: revista de sociologia da USP, São Paulo: USP, v. 26, n. 1, p. 61-73, 2014.

HOCHSCHILD, Arlie R. Love and Gold. In: EHRENREICH, Barbara; HOCHSCHILD, Arlie R. (Ed.). Global Woman: Nannies, Maids, and Sex Workers in the New Economy. New York: Metropolitan Books, 2003. p. 15-30.

IBGE. Coordenação de População e Indicadores Sociais. Síntese de indicadores sociais: uma análise das condições de vida da população brasileira: 2015. Rio de Janeiro: IBGE, 2015.

ILO. International Labour Organization. Office. Domestic workers across the world: global and regional statistics and the extent of legal protection. Geneva: ILO, 2013. Disponível em: $<$ http://www.ilo.org/wcmsp5/groups/public/---dgreports/---dcomm/---

publ/documents/publication/wcms_173363.pdf>. Acesso em: 30 maio 2017.

ILO. International Labour Organization. Ratifications of C189 - Domestic Workers Convention, 2011 (No. 189). Genève: ILO, 05 Sept. 2013 Disponível em:

$<$ http://www.ilo.org/dyn/normlex/en/f?p=

NORMLEXPUB:11300:0::NO::P11300_INSTRUMENT_ID:2551460>. Acesso em: 30 maio 2017

KERGOAT, Danièle. Divisão sexual do trabalho e relações sociais de sexo. In: HIRATA, Helena et al. (Org.). Dicionário Crítico do Feminismo. São Paulo: Unesp, 2009. p. 67-75.

LUCA, Carlos Moreira de. Relação de emprego doméstico: o contrato de emprego doméstico no direito brasileiro do trabalho. 1980. Dissertação (Mestrado em Direito) - Universidade de São Paulo, São Paulo, 1980. 
MACEDO, Renata Guedes Mourão. Espelho mágico: empregadas domésticas, consumo e mídia. 2013. Dissertação (Mestrado em Antropologia Social) - Universidade de São Paulo, São Paulo, 2013.

MAIOR, Jorge Luiz Souto. Curso de direito do trabalho: a relação de emprego. v. II. São Paulo: LTr, 2008.

MELO, Patrícia Campos. Empresa 'importa' babás e domésticas das Filipinas para o Brasil. Cotidiano. Folha de S.Paulo, São Paulo, 10 maio 2015. Disponível em: $<$ http://www1.folha.uol.com.br/cotidiano/2015/05/1627108-empresa-importa-babas-edomesticas-das-filipinas-para-o-brasil.shtml>. Acesso em: 15 nov. 2016.

MENDES, Gisele Santoro Trigueiro. Trabalhadores domésticos: férias e "diaristas". Brasília, abr. 2001, p. 04 (Consultoria Legislativa). Disponível em:

$<$ http://www2.camara.leg.br/documentos-e-pesquisa/ publicacoes/estnottec/arquivospdf/pdf/101994.pdf $>$. Acesso em: 25 jan. 2017.

MONTAL, Zélia Maria Cardoso; GAMBA, Juliane Caravieri Martins. Tutela jurídica do trabalho da mulher: principais aspectos da condição feminina no mundo do trabalho. Revista LTr: legislação do trabalho, São Paulo, v. 77, n. 9, p. 1083-1091, set. 2013.

MOREIRA, Mateus; DIAS, Tatiana. O que é 'lugar de fala' e como ele é aplicado no debate público. Artigos e Reflexões. Geledés, São Paulo, 16 mar. 2017. Disponível em:

$<$ http://www.geledes.org.br/o-que-e-lugar-de-fala-e-como-ele-e-aplicado-no-debatepublico/\#gs.X7rJhz8>. Acesso em: 06 maio 2017.

NORBIM, Fernando Dalvi; NORBIM, Luciano Dalvi. Nova Lei do Empregado Doméstico comentada e destacada. Campo Grande: Contemplar, 2015.

NOYÉ, Sophie. Hacia un feminismo materialista y queer. Traduzido por Carmen Cohen. Democracia Socialista, 16 maio 2015. Disponível em:

$<$ http://www.democraciasocialista.org/?p=4599>. Acesso em: 05 nov. 2015.

NUNES, Christiane Girard Ferreira. Cidadania e Cultura: o universo das empregadas domésticas em Brasília (1970 - 1990). 1993. Tese (Doutorado em Sociologia) - Universidade de Brasília, Brasília, 1993.

NUNES, Raquel Portugal. Autodiscriminação: o inimigo dentro do trabalhador. In: VIANA, Márcio Túlio; RENAULT, Luiz Otávio Linhares (Coord.). Discriminação. São Paulo: LTr, 2000. p. 467-471.

OIT. La igualdad en el trabajo: afrontar los retos que se plantean. Informe global con arreglo al seguimiento de la Declaración de la OIT relativa a los principios y derechos fundamentales en el trabajo. In: Conferencia Internacional del Trabajo, 96.a reunión, 2007. Ginebra: OIT, 2007. Disponível em:

$<$ http://www.oitbrasil.org.br/sites/default/files/topic/discrimination/pub/relatorio_global_2007 _atualizacao_233.pdf $>$. Acesso em: 21 maio 2017.

OIT. Organização Internacional do Trabalho. Convenção e Recomendação sobre Trabalho Decente para as Trabalhadoras e os Trabalhadores Domésticos. Genebra: OIT, 2011. Disponível em: 
$<$ http://www.oit.org.br/sites/default/files/topic/gender/pub/trabalho_domestico_nota_5_565_7 39.pdf>. Acesso em: 30 maio 2017.

OLIVEIRA, Creuza. Luta e resistência para a valorização do trabalho doméstico. In: RIBEIRO, Matilde (Coord.). As políticas de igualdade racial: reflexões e perspectivas. São Paulo: Perseu Abramo, 2012. p. 93-97.

ORIONE, Marcus; BIONDI, Pablo. Uma leitura marxista do trabalho doméstico. Revista LTr, v. 75, p. 311-317, 2011.

ORR, Judith. Marxismo e feminismo hoje. Lutas Sociais: Revista do Núcleo de Estudos de Ideologias e Lutas Sociais (NEILS), São Paulo: PUCSP, n. 27, p. 132-143, $2^{\circ}$ sem. 2011.

PINHEIRO, Luana Simões et al. Nota técnica - Mulheres e trabalho: breve análise do período 2004-2014. n. 24. Brasília: Ipea, 2016.

PINTO E SILVA, Otávio. O fim do "servicinho". Opinião. Folha de São Paulo, São Paulo, 23 mar. 2013. Disponível em: $<$ http://www1.folha.uol.com.br/opiniao/2013/03/1253287-betoricha-um-pacto-para-reduzir-desigualdades.shtml>. Acesso em: 22 fev. 2017.

PIOVESAN, Flávia. Direitos Humanos e o Direito Constitucional Internacional. 7. ed. São Paulo: Saraiva, 2006.

PRADO JR., Caio. Formação do Brasil contemporâneo: colônia. 23. ed. São Paulo: Brasiliense, 2007.

REVERBEL, Paula. Itamaraty exclui de concurso 47 candidatos autodeclarados negros. Mundo. Folha de S.Paulo, São Paulo, 12 set. 2016. Disponível em:

$<$ http://www1.folha.uol.com.br/mundo/2016/09/1812385-itamaraty-exclui-de-concurso-47candidatos-autodeclarados-negros.shtml>. Acesso em: 06 nov. 2016.

SAFFIOTI, Heleieth Iara Bongiovani. Emprego doméstico e capitalismo. Petrópolis: Vozes, 1978.

A mulher na sociedade de classes: mito e realidade. 3. ed. São Paulo: Expressão Popular, 2013.

SEIFFARTH, Marlene. Organising against Intersecting Injustices: Domestic Workers' Struggle for Equal Rights in Brazil. 2014. Dissertation (Master of Science) - University of London, London, 2014.

SIBI. Sistema Integrado de Bibliotecas - Universidade de São Paulo. Dedalus. São Paulo, 2017. Disponível em:

$<$ http://dedalus.usp.br/F/P58185MINSU3J5UX2R2P9QPHQRYHCHMC27DM87KIDDF R6HHVK2-48872?RN=794954223\&pds_handle=GUEST>. Acesso em: 24 mar. 2017.

SILVA, Isadora Brandão Araujo da. Da invisibilização ao reconhecimento institucional: limites da proteção jurídica das empregadas domésticas. 2016. Dissertação (Mestrado em Direito) - Universidade de São Paulo, São Paulo, 2016.

SILVA, Jose Afonso da. Curso de Direito Constitucional Positivo. 22. ed. São Paulo: Malheiros, 2005. 
SILVA, Rafael Ioriatti da. A inconstitucionalidade ou inconvencionalidade parcial do art. 46 da Lei Complementar 150 de $1^{\circ}$ de junho de 2015. Constitucional. Ambito Jurídico, São Paulo, 27 jun. 2017. Disponível em: $<\mathrm{http} / /$ www.ambitojuridico.com.br/site/?n_link= revista_artigos_leitura\&artigo_id=16184>. Acesso em: 03 maio 2017.

SOARES, Elza. A carne. Do cóccix até o pescoço. São Paulo: Tratore. 2002.

SOUZA JÚNIOR, Antonio Umberto de. O novo direito do trabalho doméstico. São Paulo: Saraiva, 2015.

SPIVAK, Gayatri Chakravorty. Pode o subalterno falar? Disponível em:

$<$ https://joaocamillopenna.files.wordpress.com/2013/10/spivak-pode-o-subalterno-falar.pdf $>$. Acesso em: 06 maio 2017.

TELES, Lorena Feres da Silva. Libertas Entre Sobrados: Mulheres Negras e Trabalho Doméstico em São Paulo (1880-1920). São Paulo: Alameda, 2014.

THOME, Candy Florencio. O princípio da igualdade em gênero e a participação das mulheres nas organizações sindicais de trabalhadores. 2012. Tese (Doutorado em Direito) Universidade de São Paulo, São Paulo, 2012.

. La división sexuada del trabajo doméstico y su regulación legal en Brasil, Argentina y Uruguay. Derecho y Cambio Social, v. 38, p. 1-33, 2014.

UNICEF BRASIL. Convenção sobre os Direitos da Criança. Adotada em Assembleia Geral das Nações Unidas em 20 de novembro de 1989. Brasília, 2016. Disponível em:

$<$ http://www.unicef.org/brazil/pt/resources_10120.htm>. Acesso em: 12 out. 2016.

VARELLA, Santiago Falluh. Discriminação racial indireta e ação afirmativa no emprego sob a perspectiva dos direitos coletivos. 2009. Tese (Doutorado em Ciências Sociais) Universidade de Brasília, Brasília, 2009.

VIANA, Márcio Túlio; RENAULT, Luiz Otávio Linhares; CANTELLI, Paula Oliveira. Apresentação. In: (Coord.). Discriminação. 2. ed. São Paulo: LTr, 2010.

VIEIRA, Regina Stela Corrêa. Saúde e Segurança no Trabalho das Mulheres: A perspectiva de gênero para a proteção e promoção do meio ambiente laboral equilibrado. 2014.

Dissertação (Mestrado em Direito) - Universidade de São Paulo, São Paulo, 2014.

VILLATORE, Marco Antônio César. Inovações no direito do trabalho doméstico: teoria e prática. Curitiba: Juruá, 2016.

WOODS, Alan. Marxismo versus feminismo: a luta de classes e a emancipação da mulher. Traduzido por Ruy Penna. Esquerda Marxista. São Paulo, jan. 2013. Disponível em: $<$ http://www.marxismo.org.br/content/marxismo-versus-feminismo-a-luta-de-classes-e-aemancipacao-da-mulher/>. Acesso em: 22 jun. 2016. 